\title{
Service Recovery in The Australian Banking Industry
}

\author{
Fredy Valenzuela \\ University of New England \\ E-Mail: fvalenz2@une.edu.au \\ Ray Cooksey \\ University of New England \\ E-Mail: rcooksey@une.edu.au \\ Lalith Chandralal \\ University of New England \\ E-Mail: lkotuweg@myune.edu.au \\ Rumman Hassan \\ University of New England \\ E-Mail: rhassan3@une.edu.au
}

\begin{abstract}
Considering the importance of service recovery as a corrective measure for service failures, this paper explores: (a) when Australian customers complain (b) the process they follow to look for solutions to their complaints and (c) how they evaluate banks' service recovery efforts. To address these objectives, 25 in-depth interviews were conducted with Australian retail banking customers. Results show that the main reasons for complaints were incorrect transactions, performance not meeting expectations, and unfair fees. The study also showed that Australian customers perceive two steps of the complaining process are very important to have a control over the complaint: gathering all required information and lodging a complaint in person. In relation to evaluating banks' service recovery efforts, Australian customers felt that banks were not paying much attention to their complaints and that there was a lack of acknowledgement and responsiveness.
\end{abstract}

Keywords: Service Recovery, Complaining Behavior, Customer Satisfaction 


\section{INTRODUCTION}

Despite the consensus regarding the importance of offering high quality services, service failure remains problematic for almost every business in the world (Ennew \& Shoefer, 2004). The prevalence of service failure in retail service settings and the growth in importance of the service sector in the world's economy both point to the need for a better understanding of the role that service recovery should play in today's marketplace.

The purpose of this study is to investigate the phenomenon of service recovery and how it applies to Australian banks. The study initially addresses the issue of the importance of complaint resolution for banks. Customers share their views and describe why they think banks should make efforts to resolve their complaints.

Following this section, the paper presents a study of the various scenarios that prompt the customers to make complaints to the banks. The reasons are not all of equal magnitude or importance to the customers, and the study provides an in-depth look into these situations. The responses of the customers have been classified into crucial and minor service failures. Most of the failures which prompt customer complaints have been identified as being crucial service failures, whilst only one was classified as a minor service failure.

The steps followed by Australian customers in making complaints were also investigated. These steps were then mapped out. It was found that most customers eventually went to a branch to complain, which suggests that banks may look to trying their best to minimize the effort taken by customers to make complaints.

How customers evaluate the service recovery strategies of the banks was also studied. This predominantly addressed the issues pertaining to fairness, which comprises procedural, interactive, and distributive fairness. The findings could be incorporated by banks into their employee training programs to have more efficient and effective service recovery mechanisms in place.

In relation to the structure of the paper, first a literature review is provided, followed by the methodology. Then the paper discusses the findings of the in-depth interviews, and finally the conclusions are presented.

\section{LITERATURE REVIEW}

Service recovery has been defined as actions undertaken by service providers to address service failures and the set of processes that firms employ to attempt to provide a remedy for those failures (Battaglia, Borchardt, Sellitto \& Pereira 2012). Johnston and Michel (2008) found that an organization's service recovery procedures led to three distinct outcomes: customer, process, and employee recoveries. Michel, 
Bowen and Johnston (2009: 253) suggest to integrate customer recovery, process recovery, and employee recovery effectively for a successful service recovery, thus they define service recovery as “...the integrative actions a company takes to reestablish customer satisfaction and loyalty after a service failure (customer recovery), to ensure that failure incidents encourage learning and process improvement (process recovery) and to train and reward employees for this purpose (employee recovery)”.

Service recovery is especially important in the banking sector as highlighted by Younas and Jan (2012: 2) "Customers may avoid complaining about minor service failures, however, in the financial institutions like banks there are no minor service failures as it is the dealing of money”. Press, Ganey, and Hall (1997: 74) revealed that service recovery is one of the most important issues to banking customers and that "well handled problems or complaints produces customers who are actually more loyal than those experiencing no problems at all”. Thus, service recovery could be seen as the second opportunity a business has to make things right for a customer, as the business failed the first time to do so properly (Bowen \& Johnston, 1999). Effectively managing complaints would also have a major impact on customer satisfaction and intentions to switch (Ahmed \& Amir, 2011), as service recovery failure is considered one of the major causes behind consumers' decision to exit a service (Keaveney, 1995). This would be especially important in the context of Australian banking industry, because according to Colgate and Hedge (2001:206), "defection is not just occurring in a small isolated set of firms but is a widespread facet of the Australian banking industry”.

\section{Factors Affecting Consumers' Intention to Complain}

Service recovery is usually instigated or initiated by a complaint from a dissatisfied customer. However, over the years the trend in literature shows that only a small percentage of dissatisfied customers complain (Peppers \& Rogers, 2004). In the case of banks, although 63\% of consumers are dissatisfied with the bank services, only $11 \%$ complain to their banks (Press, Ganey, \& Hall, 1997 cited in Chebat, Davidow \& Codjovi, 2005). These figures not only show that customers more often than not tend to be averse to complaining, but also that this trend deprives companies of the opportunity of recovering from service failures. According to Malhotra, Ndubisi and Agarwal (2008), a private compliant (complaining to family members and friends without a word to the organization) has a stronger impact on defection than public complaints (complaining to the organization) in the context of retail banking sector in Malaysia. Thus, it is important to investigate the reasons and circumstances that facilitate or deter customers from complaining. 
With reference to complaining behavior in the banking industry, Valenzuela (2008) in his work on the Chilean banking industry stated that on the basis of past literature there were two plausible reasons as to why customers do not complain. The first reason was the inherent negative attitude that people have towards complaining (Davidow \& Dacin, 1997). Secondly, customers perceived that companies have a negative attitude towards complaint resolution (Lau \& Ng, 2001). Siddiqui \& Tripathi (2010) found four types of customers in terms of their complaining attitude in the context of the Indian banking sector: non-complainers, switchers, prompt complainers and positive thinkers, and the majority of the customers (61\%) belonged to the noncomplaining group. They further found that many of the customers of the noncomplaining group do not know where and how to complain. Al-Foqahaa (2010) found that customers' complaining behavior is negatively affected by lack of information as to whom they complain, perceived justice, and the expected costs and efforts of complaining in Palestine. In addition, customers' education level, frequency of bank visits and the type of problem were also found to have an impact on complaining behavior, but sex, age and income had no effect (Al-Foqahaa, 2010).

In the context of Australia, there is a dearth of studies regarding the factors affecting consumer complaining behavior towards Banks; for example, White and Yanamandram (2004) found that Australian consumers' complaint behaviour towards financial services was found to differ according to three variables, namely: account type, length of time dissatisfied, and gender. For example, (a) cheque account holders complain less frequently than other account holders, (b) the more the times that the consumer had been dissatisfied with a financial service, the higher the number of times that the consumers tend to complain, and (c) women make more complaints to financial institutions than men. They further found a number of reasons for consumers' dissatisfaction towards Australian financial institutions, such as lack of branch locations, high interest rates on loans, low interest rates on savings, long waiting times, number of account fees, high account fees, poor counter service, e-banking confusion, poor telephone banking service, and various other reasons. Colgate and Hedge (2001) found that consumers complaint at least twice before they exit their banks in Australian and New Zealand. According to Colgate and Hedge (2001), 'service failures' are the most influencing factor on consumers' propensity to complain followed by 'denied services' and then 'pricing problems', but demographic differences do not have a reasonable impact on compliant behaviour among Australian and New Zealand bank customers. Thus, from the literature review, it appears that the nature of the problem (perceived severity of the problem), attitude towards banks' complaint resolution, the level of confidence of receiving a positive outcome from the 
bank, the level of relationship with the service provider, knowledge about where to complain and how to complain, perceived easiness/complexity of complaining process, and various demographic and psychographic factors tend to be the predicting variables for complaining behaviour of banking customers. However, there are very limited studies available in the context of the Australian banking industry with reference to consumer complaining behavior, and this leads to the following research question:RQ1. When and under what circumstances do Australian banking consumers make complaints?

\section{Consumer Complaining Process}

Customer complaint behavior as can be seen from the discussion above is a fairly complex activity, and the 'modus operandi' by which customers complain is of significant importance to service providers. The complaint process normally begins with a trigger caused by an unfavorable negative incident which triggers an unfavorable service experience (Tronvoll, 2012). Kim, Wang and Mattila (2010) presented a conceptual model of customer complaining behaviour which suggests that initial dissatisfaction from a service failure leads to cognitive appraisal, which in turn will determine the consumer's coping strategies (i.e., doing nothing, complaining to a third party, spreading negative word-of-mouth, or deciding to make a complaint). If consumers make a complaint, then they evaluate the recovery effort in terms of fairness and form their recovery satisfaction judgments, which in turn will lead to behavioral outcomes such as switching, word of mouth (WOM), or loyalty.

In line with complaining behaviour, it is also significant to identify the channel(s) used by customers to complain to service providers, as various types of encounters (e.g., personal, phone, and electronic) are available for consumers to lodge complaints. Some studies in the past (Tax \& Brown, 1998) predicted that the proliferation of technology would facilitate customer complaints. For example, Tax and Brown (1998) stated that the increased accessibility of customer service personnel via mobile phones, e-mail, and toll-free numbers might encourage customers to complain, because it minimizes the time and effort required to make a complaint. Andreassen and Streukens (2012) developed a conceptual model to understand consumers' intention to adopt online complaining and found the attitude toward online complaining is positively related to the extent customers believe online complaining to be useful, easy to use, and enjoyable. They further found that the effect of attitude on intention to use online complaining is moderated by situational factors (e.g., intensity of dissatisfaction and outcome expectations ) but is not affected by individual customer characteristics (i.e., inherent novelty seeking and need for social interactions). 
Customer complaining behavior in technology-based service encounters was further studied by Snellman and Vihtkari (2003) who found that in the Finnish banking industry, there were no significant differences in the complaining rates of customers who complained via traditional means and those who complained via technologymediated service encounters. The research conducted to date suggests that more work is needed, as the findings of industry specific customer complaining behavior will have interesting implications for designers of service recovery mechanisms. Especially, more investigation is needed in the context of Australian banking customers' complaining behavior, as the existing literature clearly depicts a knowledge gap in this area. Hence, the following research question was identified in this study:

RQ2. What is the likely process that Australian banking customers tend to follow and what types of encounters do they prefer to use to complain?

\section{Customer Evaluation of Service Recovery Efforts}

How consumers evaluate service recovery efforts of service providers and what leads to higher customer satisfaction is another important aspect of academic inquiry within the broader literature of service recovery. It is well known in the service recovery literature that consumers evaluate three types of fairness when evaluate service recovery efforts: distributive justice (fairness of the outcome of the business' response), procedural justice (fairness of the process by which decisions are made), and interactional justice (fairness of the organization's representative's attitude and personal interaction with the customer) (Tax \& Brown, 1998). Hess and Ambrose (2010) extended it to a four factor model: distributive, procedural, interpersonal, and informational justice. A growing number of scholars have investigated how various aspects of these fairness dimensions impact customer satisfaction about service recovery efforts; for example, Gelbrich and Roschk (2011) empirically validated a path model depicting organizations responses (compensation, favorable employee behavior, and organizational procedures) positive influence justice perceptions (distributive, interactional, and procedural justice) which positively affect postcomplaint satisfaction (transaction-specific and cumulative satisfaction), and in turn has a positive impact on customer behavioral intentions (loyalty and positive word of mouth).

Battaglia et al. (2012) revealed that speed of recovery and empowerment are important aspects of service recovery dimensions from the perspective of a manufacturing company. Huang (2010) found that positive perceived employee effort 
to solve problems has a positive impact on customers' ratings on satisfaction, repurchase intention and favourable WOM communications about the service provider. According to Gruber, Szmigin and Voss (2009), being taken seriously in the complaint encounter and the employee's listening skills and competence are important aspects of service recovery for consumers. Hocutt, Bowers and Donavan (2006) found that consumers were most satisfied and less likely to engage in negative word of mouth under conditions of high responsiveness (i.e., least amount of time taken for service recovery) and courtesy. Younas and Jan (2012) also found that prompt response, material compensation and politeness of employees play important roles in service recovery evaluations in the banking industry in Sweden. Similarly, in a study conducted in the context of the US retail-banking sector, Duffy, Miller and Bexley in 2006 found that consumer satisfaction level was significantly affected by the nature and type of the recovery strategy used by the bank, but no significant difference in recovery strategies or satisfaction by customer age, gender, or tenure with the bank. McCollough, Berry and Yadav (2000) showed that customer satisfaction was lower after service recovery than in the case of error-free service. This reinforced the importance of 'doing it right the first time'.

In the context of Australia, AS 4269: Australia complaints handling standard (currently adopting AS-ISO-10002-2006) provides 13 'essential elements' of effective complaints handling: commitment, fairness, resources, visibility, access, assistance, responsiveness, no charges, remedies, data collection, systemic and recurring problems, accountability, and review of which 8 elements fall into front-office and the remaining 5 belong to back-office category (Buttle \& Thomas, 2003). However, Buttle and Thomas (2003) found that most of the companies, including the banks, chosen for their study in Australia comply poorly with AS 4269 standards, both overall and in respect of most of the individual elements. Their results are consistent with the findings of Colgate and Hedge (2001) who found that around 65\% of the respondents of their study were dissatisfied with the outcome of their complaint in the context of the Australian and New Zealand banking sectors. They further found that dissatisfactory service recovery effort of the banks was the major reason for the switching behaviour of consumers.

However, these limited research efforts are completely inadequate to identify how consumers evaluate service recovery efforts of Austrian banks. Thus, further academic inquiries are needed to understand (a) the important aspects/attributes of service recovery efforts of Australian banks for consumers, (b) how they evaluate such service recovery efforts of banks, and (c) to what extent are they satisfied with these aspects. Findings of such academic efforts will be of immense benefit to 
Australian banks to improve service recovery practices; hence, this paper aims to address the third research question as shown below.

RQ3. How do Australian customers evaluate service recovery efforts of banks?

\section{METHODOLOGY}

The investigation employed one-on-one, semi-structured, in-depth, qualitative interviews. The topical landscape for the interview included two different types of issues, namely: i) overall comments about complaining to financial institutions and ii) complaining behavior. The number of participants interviewed was 25. After conducting 20 interviews, convergence of opinions amongst the respondents began to surface, hence the information obtained was considered sufficient to address the goal of this study. Researchers have recommended continuing to undertake qualitative focused interviews until saturation or redundancy is reached in the interpretation of categories that emerge from respondents' opinions (Strauss \& Corbin, 1998). However, as recommended by Yanamandram and White (2006), even though convergence started to occur at the 20 interviews mark, an additional five qualitative focused interviews were undertaken to decrease the chance of new information being missed. Participants for the study were chosen using 'purposive sampling'. The participants were sourced from inhabitants of Australia and the cities of Sydney, Melbourne and Armidale. The main criteria for inviting participants to the study were for the potential participant: a) to be over 18yr, b) to be a customer from the retail banking industry (e.g., to have a credit card, mortgage, etc.) and c) to have experienced a service failure with their bank. Thematic content analysis was undertaken to explore the themes and issues emerging from the data. The constant comparative technique (Glaser \& Strauss, 1967) was employed simultaneously with data collection to facilitate more rigorous analysis. This technique involved reading and re-reading transcripts again and again along with emerging new data to find and refine the themes and categories. Qualitative data analysis software (MAXQDA 10 Plus) was employed to manage the process of analysis, as sample size was comparatively large.

In relation to the interview process, before undertaking the in-depth interviews, approval was obtained from UNE Human Research Ethics Committee (HE12-086). To select participants, potential participants' contact details were gathered using personal contacts, official websites of companies and professionals who provide contact details, and collecting visiting cards of prospective participants by personally visiting their offices. After collecting the contact details, the researcher emailed 
prospective participants and explained the nature and purpose of the study and requested the prospective participant for an interview at a later time. If the prospective participant expressed his or her willingness to participate, the researcher provided the information sheet and arranged a convenient time and place for the interview (e.g., their offices or home). A consent form was given to the participant before the commencement of the interview so that the participant could choose to participate by signing the consent form or by recording their informed consent at the beginning of the interview. All the interviews were conducted face-to-face and digitally recorded, with informed consent from the participant. The average length of each interview was 25 minutes. Once all interviews were finished, each interview was transcribed (verbal content only) and stored in a Word document. This process was undertaken by two researchers to make sure no mistake was made and that the transcripts were $100 \%$ accurate.

\section{FINDINGS}

Analysis of the transcripts of the interviews revealed a number of themes and issues which could be classified as (1) under what circumstances Australian customers complain, (2) steps followed by Australian customers during the complaining process and (3) customers' evaluation of banks' service recovery efforts. The following sections discuss these emergent themes in greater detail.

\section{When Do Australian Customers Complain?}

Much of the literature states that customers are more prone to complain when the failure results in significant loss on their part, and also when they expect fairness and resolution from the service providers. The present study revealed that customers tend to complain due to disappointment caused by either critical service failures or minor service errors.

\section{- Critical Service Failures}

The majority of participants (17 in total) stated that their complaints were due to service failures that were critical in nature. The following is the discussion of the nature of these failures.

1. Perceived performance not meeting customer expectations (not delivering promised services). In marketing terms, dissatisfaction occurs when companies are not able to meet customers' expectations. Quite often this also results from not being able to deliver what was promised to the customer. As customer 
expectations are formed by promises made by the banks, when the banks are not able to fulfill those promises customers tend to be dissatisfied with them.

This phenomenon of customer dissatisfaction is highlighted by the experience of participant 13 who was extremely dissatisfied with Bank A, a major Australian bank. The respondent stated that after applying for a home loan and receiving his pre-approval he was told that the final loan will be approved once the valuation of the property was done within 3 days. However, this never happened and ultimately the respondent had to go to Bank B for a home loan. The respondent who had been a customer of Bank A for over 5 years was extremely disappointed with Bank A's inability to keep their promise. His dissatisfaction was compounded by the fact that even after repeated complaints the problem was not resolved, and the bank performed extremely poorly especially along the lines of communicating with the client.

2. Wrong transactions and wrong execution of services. Interviews revealed that customers tended to complain when they felt that they had been incorrectly charged for services that they received or in some cases for services they did not receive. Participant 9 highlighted this experience by stating that he was charged for car insurance by Bank A for years even after the stipulated period of one year. The participant had to go through a lot of stress and trouble to resolve this matter. This scenario highlighted not only the mistake made by the bank, but also the extreme inconvenience that the customer had to deal with to resolve this issue.

3. Not providing important/correct information about the products and policies. Often customers did not understand the policies and procedures of the banks. The use of business jargon did not make this any easier for the layperson. From participants' perspectives, the onus was on banks to clearly explain their policies and procedures to its customers. Quite often, when this transparency was not forthcoming, it created problems and resulted in customer complaints. This could consequently become a major cause of concern for the customer when the amount at stake was quite high, which resulted in a sense of higher perceived risk.

4. Poor customer service and less friendly staff. For customers to be satisfied it is imperative that service providers show an adequate level of empathy towards them. This should translate into courtesy and responsiveness amongst other things. The lack of any of these will only pave the way for customer dissatisfaction and complaint. Although much has been written about empathy and responsiveness in 
service marketing literature, it appears to be something that certain banks lack in their service mantra.

5. System failures. Technological glitches and failures are often a cause of customer dissatisfaction and customer complaints. Situations which involve ATMs being out of order or temporary disruption of electronic services are not necessarily viewed as being major causes of customer dissatisfaction. However, major problems with technology over a prolonged period of time are a major cause of concern and dissatisfaction.

\section{- Minor service errors}

The interviews revealed a few incidents that were fairly minor in comparison to the ones discussed earlier, but nonetheless resulted in customer complaints. Charging annual fees on credit cards when the bank was not supposed to, charging an account keeping fee for accounts that are supposed to be free, and incorrectly charging a late payment fee on a credit card were some of the scenarios reported by the customers.

\section{What are the Key Steps of the Complaining Process?}

Based on the responses of the participants, the study showed that 10 overall steps in the service recovery process seemed to be relevant to the participants, namely: 1 ) Identification of the problem, 2) Deciding whether or not to complain, 3) Collecting information, 4) Making the complaint over the phone or email, 5) Waiting for the results, 6) Trying to get feedback by contacting bank staff over phone or through email, 7) If the response is not satisfactory, personally visiting the bank and make the complaint again, 8) If the response is not satisfactory, bringing the complaint to next level of management, 9) Waiting for results, and 10) Behavioral consequences based on the bank response to the complaint

However, not all these steps were equally important to customers. Results show that two of these steps (i.e., complaining in person and gathering all required information) were the ones most mentioned by participants. Seven participants indicated that personally visiting the bank was the most important step due to reasons such as they felt they could obtain personal attention to the problem, they could have the problem properly explained to them, and they thought they would have a greater chance in having the problem resolved. Four participants mentioned gathering necessary information to make the complaint is the most important, because they tend to have more control over the complaint. Similarly, another two participants highlighted that bringing the complaint to the right person who could make decisions 
was the most important thing, for example, complaining to the higher management level directly or lodging a formal complaint, etc.

\section{How do Australian Customer' Evaluate Service Recovery Efforts by a Bank?}

One of the aims of this study was to investigate the manner in which customers evaluated the service recovery efforts of the banks. For this purpose, participants were asked to recall memorable experiences when complaining. A substantive proportion of the examples given by participants were related to negative experiences (16 out of 25). The other experiences corresponded to either positive or mixed evaluations (6 and 3, respectively).

Several service recovery dimensions emerged from the interviews. The following sections present results focused on these critical dimensions.

\section{- Procedural Fairness}

Procedural fairness, as it appears in marketing literature, relates to how customers perceive the fairness of the service recovery process (Davidow, 2000). If customers felt that the processes in place did not resolve, or actually hindered, the service recovery process, they tended to be dissatisfied. The following discussion illustrates what some participants had to say about this type of fairness.

Having had to put in an unreasonable amount of time:

For 10-15 minutes when you call them all you will hear is music (participant 13).

Having had to put in an unreasonable effort:

I do put in some effort. I call them quite a few times and then I had to go there in person, so that was a lot of effort from me (participant 24).

Did not provide proper information and feedback about the progress:

They are supposed to send me a letter with the outcome, but so far I haven't got any letter from them (participant 6). Not flexible enough to solve problems:

There are people who are also late sometimes in making their payment and when

they call the bank there is way by which they can waive the fee (participant 8).

Took a long time to solve the problem:

What should have taken two hours took three days (participant 16).

Most of the responses of the customer clearly signaled the lack of procedural fairness resulting from various policies that were heavily tilted in the favor of the bank. Thus, it made it difficult for the customers to resolve their issues, which in turn led to their dissatisfaction. 


\section{- Interactional Fairness}

This refers to the general treatment that respondents receive from the employees of the service organization (Davidow, 2000). Empathy, attention, responsiveness, and so on are facets of employee actions that determine interactional fairness. The following are the experiences of some participants pertaining to interactional fairness, or the lack of it, that prevailed in various Australian banks they had to deal with.

Did not give a fair/adequate attention to the problem/complaint:

It felt like it wasn't a big concern for them (participant 21).

Did not show a genuine interest to solve the problem:

It's me who is always knocking but they are not coming back to me (participant 9).

Compassion and empathy to customer:

The lady who was dealing with the situation was very compassionate about it (participant 9).

\section{- Distributive Fairness}

Not receiving a positive outcome or a desired outcome goes a long way in terms of dissatisfying a customer (Davidow, 2000). Mixed experiences were reported by participants in relation to the outcome they received as a consequence of their complaints.

Solving the problem:

When we talked to them about that they immediately recognized that we were not liars and were prompt about it (participant 15).

Did not make any acknowledgment or apology:

A simple letter or email should have been sent (participant 13).

Did not provide sufficient reasons/explanations:

They couldn't give me details of how it happened (participant 20).

Proper compensation:

They refunded my credit card within 48 hours (participant 21).

Did not inform about the final decision:

They are supposed to send me a letter with the outcome, but so far I haven't got any letter from them (participant 6). 


\section{FINAL DISCUSSION AND CONCLUSIONS}

This study examined the various facets pertaining to service recovery in Australia using thematic content analysis technique. The study focused extensively on three research questions: (a) when Australian consumers make complaints, (b) customer complaining behavior (the process), and (c) the manner in which customers evaluated the service recovery efforts undertaken by banks.

With reference to the first research question, the majority of the respondents have made complaints due to the disappointments created by critical service failures such as banks' inability to deliver promised services, wrong execution of important transactions, poor provision of important information about banking products and policies, poor customer service, less friendly staff and various types of system failures. Participants viewed the perceived magnitude of the service failure as tending to be higher when they encounter such critical service failures, thus tending to have more willingness to make complaints. This finding is consistent with the literature that shows consumers have more willingness to complain if the magnitude of the problem is more severe (Lala \& Priluck, 2011). However, findings also revealed that some participants have complained even when they had encountered minor service failures, such as charging unnecessary or unfair fees and charges by the bank. This can be explained from the claim that even minor issues are important to consumers in the banking context, as it concerns the dealing of money (Younas \& Jan, 2012). Similarly, Rich (2004: 9) questions the legality of the increasingly high level of penalty fees regularly charged by Australian banks and "calls for Australian banks to release sufficient data to enable the Australian public to assess the validity”.

The above findings suggest banks should make an effort to deliver their service right the first time to prevent disappointing service experiences for consumers. Managerial efforts such as blue printing the service process to identify error points, undertaking process reengineering to simplify the processes, providing proper training to employees to deliver services to meet customer expectations, avoiding over promising and provisioning of proper and correct information for customers all will be important for prevention of such negative incidents. Sufficient attention should be paid to prevent even minor errors from marinating outstanding service experiences to consumers, which will reduce the number complaints and the associated costs of service recoveries.

This study also mapped out the customer complaining process undertaken by the Australian customers. Findings revealed that participants go through an extended process of complaining, shown elsewhere in this paper, which starts with problem identification and ends with behavioural responses based on the outcomes of the 
complaint. This process is very consistent with the conceptual model of customer complaining behaviour presented by Kim, Wang and Mattila (2010). However, findings further revealed that two aspects of the above mentioned process are most important to majority of the participants: (a) gathering all the required information and (b) personally visiting the bank to make the complaint. The underlying reasons expressed by the participants were: first, they tend to have more control over the complaint when they have all the necessary information and, second, there seems to be a greater chance of obtaining a tangible outcome to the complaint when they are personally present at the bank branch. This further implies that participants have a lesser degree of credibility of other options, such as complaining to customer service over the phone and email complaints. For example, generally, participants said they prefer to solve their problems via phone, but it was found that most of them felt compelled to take the trouble of going to the branch to solve their problem, because they were unable to do so using other less cumbersome avenues. This is something that banks can look into to make the complaint process simpler and more efficient. Especially, banks need to improve consumers confidence in these other modes of complaining through awareness and promotional campaigns but, most importantly, to deliver what banks promise through such promotional campaigns, because the majority of Australian participants expressed their dissatisfaction about the disappointing experiences with those complaining options.

Finally, the study investigated how Australian customers evaluated the service recovery efforts of banks. The concepts pertaining to fairness (procedural, interactive, and distributive) were found to be highly relevant in studying this phenomenon which is again consistent with the existing literature (Blodgett, Hill \& Tax, 1997; Tax \& Brown, 1998). Interviews revealed various instances where the customers were not happy with issues pertaining to fairness and suggested that banks needed to do a lot more to give customers the feeling of being treated with greater degrees of respect and empathy (interactive fairness). The lack of responsiveness and acknowledgement of the complaint was also a major negative, as suggested by the customers, which are very important aspects taken into consideration by consumers when evaluating service recovery efforts, as previously suggested by other scholars (Komunda \& Osarenkhoe, 2012). The findings further revealed that customers perceive that they are spending too much time and effort looking for solutions to complaints. This is another important aspect for improvement, because speed of recovery is a crucial aspect for consumers, which belongs to procedural fairness (Battaglia, Borchardt, Sellitto \& Pereira, 2012). Hence, these findings suggest areas where banks have significant room for improvement; for example, banks need to substantially improve interactive 
fairness in terms of providing proper training for employees so that they can inculcate both technical quality (ability to give correct answers and solutions to the complaints) and functional quality (ability to show personal attention and empathy towards customers), both of which are essential for effective complaint resolutions. Further, process improvements and other structural changes will be necessary for banks to speed up the service recovery solutions to enhance the customer evaluations favorably.

\section{LIMITATIONS}

This paper contributes to the service recovery literature, as it has explored consumer behaviour in the context of Australian banks' service failures and recovery efforts, on which there are very limited studies available. However, the generalizability of these findings to a wider population is limited due to the exploratory nature of the study, thus more quantitative inquires are needed to validate these findings.

\section{REFERENCES}

Ahmed, I., \& Amir, M. (2011). Service Quality; Service Features and Customer Complaint Handling As the Major Drivers of Customer Satisfaction in Banking Sector of Pakistan. International Review of Business Research Papers, 7(1), 313318.

Al-Foqahaa, S. (2010). Situational Dimensions of Customers Complaining Behavior when Dissatisfied with Banking Services in Palestine. An-Najah University Journal for Research, 24(9), 2657-2690.

Andreassen, T. W., \& Streukens, S. (2012). On-line Complaining: Understanding the Adoption Process and the Role of Individual and Situational Characteristics. Managing Service Quality, 23(1), 1-1.

Battaglia, D., Borchardt, M., Sellitto, M. A., \& Pereira, G. M. (2012). Service recovery: a method for assessing performance. Business Process Management Journal, 18(6), 5-5. http://dx.doi.org/10.1108/14637151211283366

Blodgett, J. G., Hill, D. J., \& Tax, S. S. (1997). The effects of distributive, procedural, and interactional justice on postcomplaint behavior. Journal of Retailing, 73(2), 185-210. http://dx.doi.org/10.1016/S0022-4359(97)90003-8

Bowen, D., \& Johnston, R. (1999). Internal service recovery: developing a new construct. International Journal of Service Industry Management, 10(2), 118-131. http://dx.doi.org/10.1108/09564239910264307 
Buttle, F., \& Thomas, L. (2003). Complaints Handling in Australia: Evidence from Organisational Websites. Paper presented at the Proceedings of Australian and New Zealand Marketing Academy (ANZMAC) Conference, Adelaide.

Chebat, J. C., Davidow, M., \& Codjovi, I. (2005). Silent Voices Why Some Dissatisfied Consumers Fail to Complain. Journal of Service Research, 7(4), 328-342. http://dx.doi.org/10.1177/1094670504273965

Colgate, M., \& Hedge, R. (2001). An investigation into the switching process in retail banking services. International Journal of Bank Marketing, 19(5), 201-212. http://dx.doi.org/10.1108/02652320110400888

Davidow, M. (2000). The bottom line impact of organizational responses to customers complaints. Journal of Hospitality and Tourism Research, 24(4), 473-490. http:// dx.doi.org/10.1177/109634800002400404

Davidow, M., \& Dacin, P. (1997). Understanding and encouraging consumer complaint behaviour: Improving organizational complaint management, Advances in Consumer Research, eds Brucks, M. and MacInnis, D., Association for Consumer Research, 24, 450-456.

Duffy, J. A. M., Miller, J. M., \& Bexley, J. B. (2006). Banking customers' varied reactions to service recovery strategies. The International Journal of Bank Marketing, 24(2/3). http://dx.doi.org/10.1108/02652320610649923

Ennew, C \& Shoefer, K. (2004), Service Failure and Service Recovery in Tourism: A review, The Tourist: A Psychological Perspective, Raj.

Gelbrich, K., \& Roschk, H. (2011). A meta-analysis of organizational complaint handling and customer responses. Journal of Service Research, 14(1), 24-43. http://dx.doi.org/10.1177/1094670510387914

Glaser, B.G. \& Strauss, A.L. (1967). The discovery of grounded theory: Strategies for qualitative research, New York: Aldine.

Gruber, T., Szmigin, I., \& Voss, R. (2009). Developing a deeper understanding of the attributes of effective customer contact employees in personal complainthandling encounters. Journal of Services Marketing, 23(6), 422-435. http://dx.doi.org/10.1108/08876040910985889

Hess, Jr. R. L., \& Ambrose, M. (2010). The Four Factor Model of Justice: An Application to Customer Complaint Handling. Paper presented at the 9th International Business and Economy Conference.

Hocutt, M. A., Bowers, M. R., \& Donavan, D. T. (2006). The art of service recovery: fact or fiction? Journal of Services Marketing, 20(3), 199-207. http:// dx.doi.org/10.1108/08876040610665652 
Huang, W. H. (2010). Other-customer failure: Effects of perceived employee effort and compensation on complainer and non-complainer service evaluations. Journal of Service Management, 21(2), 191-211. http:// dx.doi.org/10.1108/09564231011039286

Johnston, R., \& Michel, S. (2008). Three outcomes of service recovery: Customer recovery, process recovery and employee recovery. International Journal of Operations \& Production $\quad$ Management, 28(1), 79-99. http://dx.doi.org/10.1108/01443570810841112

Keaveney, S. (1995). Customer switching behavior in service industries: an exploratory study. Journal of Marketing, 59, 71-82. http:// dx.doi.org/10.2307/1252074

Kim, M. G., Wang, C., \& Mattila, A. S. (2010). The relationship between consumer complaining behavior and service recovery: An integrative review. International Journal of Contemporary Hospitality Management, 22(7), 975-991. http:// dx.doi.org/10.1108/09596111011066635

Komunda, M., \& Osarenkhoe, A. (2012). Remedy or cure for service failure?: Effects of service recovery on customer satisfaction and loyalty. Business Process Management Journal, 18(1), 82-103. http://dx.doi.org/10.1108/14637151211215028

Lala, V., \& Priluck, R. (2011). When Students Complain An Antecedent Model of Students' Intention to Complain. Journal of Marketing Education, 33(3), 236252. http://dx.doi.org/10.1177/0273475311420229

Lau, G., \& Ng, S. (2001). Individual and situational factors influencing negative word of mouth behaviour. Revue Canadienne des Sciences de l'Administration, 18(3), 163-178.

Malhotra, N. K., Ndubisi, N., \& Agarwal, J. (2008). Public versus private complaint behavior and customer defection in Malaysia, appraising the role of moderating factors. EsicMarket (September-December), 27-59.

McCollough, M. A., Berry, L. L., \& Yadav, M. S. (2000). An Empirical Investigation of Customer Satisfaction after Service Failure and Recovery. Journal of Service Research, 3(2), 121-137. http://dx.doi.org/10.1177/109467050032002

Michel, S., Bowen, D., \& Johnston, R. (2009). Why service recovery fails: Tensions among customer, employee, and process perspectives. Journal of Service Management, 20(3), 253-273. http://dx.doi.org/10.1108/09564230910964381

Peppers, D., \& Rogers, M. (2004). Managing Customer Relationships, Hoboken, New Jersey, USA: John Wiley and Sons, Inc. 
Press, I., Ganey, R. F., \& Hall, M. F. (1997). What's most important to customer satisfaction. ABA Banking Journal, 89(9), 73-74.

Rich, N. (2004). Unfair fees: A report into penalty fees charged by Australian banks: Consumer Law Cente Victoria.

Siddiqui, M. H., \& Tripathi, S. N. (2010). An analytical study of complaining attitudes: with reference to the banking sector. Journal of Targeting, Measurement and Analysis for Marketing, 18(2), 119-137. http://dx.doi.org/10.1057/jt.2010.2

Snellman, K., \& Vihtkari, T. (2003). Customer complaining behaviour in technologybased service encounters. International Journal of Service Industry Management, 14(2). http://dx.doi.org/10.1108/09564230310474174

Strauss, A., \& Corbin, J. (1998). Basics Of Quantitative Research: Techniques And Procedures For Developing Grounding Theory, Thousand Oaks, California: SAGE PUBLICATIONS INC.

Tax, S., \& Brown, S. (1998). Customer evaluations of service complaint experiences: Implications for relationship marketing. Journal of Marketing, 62(2), 60-76. http://dx.doi.org/10.2307/1252161

Tronvoll, B. (2012). A dynamic model of customer complaining behaviour from the perspective of service-dominant logic. European Journal of Marketing, 46(1/2), 284-305. http://dx.doi.org/10.1108/03090561211189338

Valenzuela, F. (2008). Managing Complaints in the Chilean Retail Banking. Revista Alcance, UNIVALI, Brazil. 15(1).

White, L., \& Yanamandram, V. (2004). Why customers stay: reasons and consequences of inertia in financial services. Managing Service Quality, 14(2/3), 183-194. http://dx.doi.org/10.1108/09604520410528608

Yanamandram, V., \& White, L. (2006). Switching barriers in business-to-business services: A qualitative study. International Journal of Service Industry Management, 17(2), 158-192. http://dx.doi.org/10.1108/09564230610656980

Younas, A., \& Jan, H. (2012). The Impact of Service Recovery on Customer Loyalty (Case company: Swedbank).Doctoral dissertation, University of Gävle. 
